\title{
Predictors of mortality in patients with COPD after 9 years
}

This article was published in the following Dove Press journal: International Journal of COPD

\section{Robson Prudente' \\ Estefânia Aparecida Thomé \\ Franco $^{2}$ \\ Carolina Bonfanti Mesquita' \\ Renata Ferrari' \\ Irma de Godoy' \\ Suzana Erico Tanni' \\ 'Department of Internal Medicine, São Paulo State University (UNESP), Medical School, Botucatu, São Paulo Brazil; ${ }^{2}$ University Hospital of São Paulo State University (UNESP), Medical School, Botucatu, São Paulo, Brazil}

Correspondence: Robson Prudente Department of Internal Medicine, São Paulo State University (UNESP) Medical School, Botucatu, Av. Prof Mário Rubens Guimarães Montenegro, s/n, UNESP - Campus de Botucatu, |86|8-687 Botucatu, São Paulo, Brazil Tel +55 I4 38II 6033

Email robsonapp@hcfmb.unesp.br
Background: COPD is one of the leading causes of morbidity and mortality in the world; however, the most varied amounts of clinical and laboratory characteristics acts in different ways in the mortality among over time. Therefore, this study aimed to evaluate the predictors of mortality in patients with COPD after 9 years.

Patients and methods: One hundred and thirty-three patients with COPD were assessed at baseline by spirometry, pulse oximetry $\left(\mathrm{SpO}_{2}\right)$, body composition, intensity of dyspnea, distance walked in the 6-minute walk test (6MWT), and Charlson Comorbidity Index (CCI).

Results: After 9 years, it was not possible to identify the lifetime of 4 patients who died and of 19 patients who stopped follow-up; thus, 110 patients were included in the analysis of predictors of mortality (67\% male, $65 \pm 9$ years old, and $\mathrm{FEV}_{1}: 52.5$ [40\%-73\%]). Male sex, age, $\mathrm{SpO}_{2}$, Body mass index, airway Obstruction, Dyspnea, and Exercise capacity (BODE) index, and frequency of exacerbations in the first 3 years of follow-up were considered in the model. Patients classified at baseline with BODE class 2 (HR: 2.62, 95\% CI: $1.36-5.04 ; P=0.004$ ), BODE class 3 (HR: $2.54,95 \% \mathrm{CI}: 1.15-5.61 ; P=0.02$ ), and BODE class 4 (HR: $15.35,95 \% \mathrm{CI}$ : 3.11-75.75; $P=0.001$ ) showed increased risk of death compared to those with BODE class 1 . The CCI (HR: $1.29,95 \%$ CI: $1.00-1.68 ; P=0.04$ ) and the number of exacerbations in the first 3 years (HR: $1.32,95 \%$ CI: $1.00-1.76 ; P=0.04$ ) also showed increased risk of death. By replacing the BODE index for the variables that compose it, those with body mass index $\leq 21 \mathrm{~kg} / \mathrm{m}^{2}$ showed increased risk of death compared to those with body mass index (BMI) $>21 \mathrm{~kg} / \mathrm{m}^{2}$ (HR: 2.70, 95\% CI: $1.38-5.25 ; P=0.003)$.

Conclusion: After 9 years, we identified that those with high BODE index, greater CCI, greater frequency of exacerbations in the first 3 years, and BMI $\leq 21 \mathrm{~kg} / \mathrm{m}^{2}$ showed increased risk of death.

Keywords: COPD, disease severity index, mortality

\section{Introduction}

COPD is one of the leading causes of morbidity and mortality in the world. ${ }^{1,2}$ In Brazil, the number of deaths by the disease showed a significant increase between 1980 and $1990,{ }^{3}$ with a tendency toward stabilization between 1989 and $2009 ;{ }^{4}$ however, it is still estimated that, by 2030, COPD will be the third leading cause of death worldwide. ${ }^{1,2}$

The main factors that increase the risk of mortality of patients with COPD are frequent exacerbations, ${ }^{5}$ need for hospitalization,,${ }^{6,7}$ presence of comorbidities,${ }^{8-10}$ low body weight, ${ }^{11,12}$ and severe airflow obstruction. ${ }^{13}$ In addition, the indexes that assess COPD systemically, such as the Body mass index, airway Obstruction, Dyspnea, and Exercise capacity (BODE) have been very useful to predict mortality in this population. ${ }^{14-16}$ 
Thus, several studies have shown the characteristics that may lead to the mortality of patients with COPD in followups of 1 year after exacerbation ${ }^{17}$ or in longer ones, such as 5 years of follow-up of stable COPD ${ }^{18}$ However, the most varied amounts of clinical and laboratory characteristics acts in different ways in the mortality among over time. Therefore, identifying which characteristics are the most influential in longer longitudinal follow-ups is necessary for conducting personalized treatment of these patients with COPD. Similarly, Brazilian studies indicate similar behaviors to those of international studies in mortality by COPD in periods of 5, 7, and 10 years; however, data from longitudinal follow-ups of patients with COPD in Brazil are still rare. ${ }^{13,19-22}$ Thus, by outlining the follow-up of this population for 9 years, we may determine whether the predictors of mortality of the disease maintain the same patterns described by international researchers in longer periods. ${ }^{5-16}$

\section{Objective}

The objective of this study was to evaluate the predictors of mortality in patients with COPD after 9 years.

\section{Patients and methods}

After obtaining approval by the Research Ethics Committee of the School of Medicine of Botucatu and signing of the informed consent form, 133 patients with COPD were recruited from the outpatient clinic of pulmonology of the Botucatu Medical School University Hospital. All patients were recruited consecutively from the outpatient clinic of a single institution between July 2004 and August 2006. Inclusion criteria were: patients diagnosed with COPD (clinical history and confirmation by the presence of airflow obstruction in post-bronchodilator spirometry); clinical stability (absence of exacerbation 3 months before the assessment of the markers); and optimized drug therapy, including long-term oxygen therapy at home. Exclusion criteria were: patients with asthma (increase greater than $12 \%$ or $200 \mathrm{~mL}$ in $\mathrm{FEV}_{1}$ after bronchodilator administration); diagnoses of other respiratory diseases (sleep apnea/hypopnea syndrome, lung cancer); noncompliance with treatment; and myocardial infarction 4 months before the beginning of the study, unstable angina, or congestive heart failure class III and IV.

At baseline, the 133 recruited patients were assessed by pulse oximetry, pulmonary function, nutritional evaluation, exercise tolerance, sensation of dyspnea, and presence of comorbidities.

The regular follow-up of these patients took place for 9 years by medical appointments at least every 6 months and by telephone contact with the survivors who had stopped outpatient medical follow-up. Besides, telephone contact was used to confirm the cause of death by family members and to confirm the clinical condition, frequency of exacerbations, hospitalizations, use of medicines, and smoking status. In addition to telephone contact, all notes by health professionals in the medical records of the patients were also used for confirmation of the information.

The number of exacerbations was considered only in the first 3 years of follow-up, since in these 3 years it is possible to count the exacerbations with greater accuracy.

\section{Pulse oximetry and pulmonary function}

Pulse oximetry was obtained by a portable pulse oximeter (Onyx - Model 9500 Oximeter; Nonin Medical Inc., Minneapolis, MN, USA) and spirometry was obtained in a computerized system of pulmonary function (Ferraris KOKO; Pulmonary Data Services Inc., Louisville, CO, USA) according to the criteria established by the American Thoracic Society in 1987..$^{23}$ The values of $\mathrm{FEV}_{1}$ and $\mathrm{FVC}$ in liters plus the $\mathrm{FEV}_{1} /$ FVC ratio before and after administration of $400 \mathrm{mcg}$ of salbutamol by inhalation were determined. $\mathrm{FEV}_{1}$ and $\mathrm{FVC}$ were also expressed in percentages of the reference values. ${ }^{24}$ The 2004 GOLD classification was considered, ie, $\mathrm{FEV}_{1} / \mathrm{FVC}<0.70-$ $\mathrm{FEV}_{1} \geq 80 \%$ of the predicted: mild; $50 \% \leq \mathrm{FEV}_{1}<80 \%$ of the predicted: moderate; $30 \% \leq \mathrm{FEV}_{1}<50 \%$ of the predicted: severe; $\mathrm{FEV}_{1}<30 \%$ of the predicted: very severe.

\section{Nutritional assessment}

The evaluation of body composition was performed by anthropometry (height and weight determined by stadiometer and Filizola ${ }^{\circledR}$ electronic scale, respectively, with patients in standing position, without shoes, and in light clothes). The body mass index (BMI) was calculated by the ratio between weight in kilograms $(\mathrm{kg})$ and height in square meters $\left(\mathrm{m}^{2}\right)$ and by bioelectrical impedance analysis (resistance was measured on the right side of the body by placing four surface electrodes in the fist and dorsal region of the foot BIA 101; RJL Systems, Detroit, MI, USA). ${ }^{25}$ Before the measurements, participants were told to empty their bladder, rest for 30 minutes, and remove all metal objects from their body. Fat-free mass (FFM) was estimated by the equation developed for individuals with respiratory insufficiency: FFM $=-6.06+($ height $\times 0.283)+($ weight $\times 0.207)-($ resistance $\times$ $0.024)+[\operatorname{sex}($ male $=1$, female $=0) \times 4.036] .{ }^{26}$ The FFM index (FFMI) was calculated by the ratio between FFM in $\mathrm{kg}$ and height in $\mathrm{m}^{2}$ (FFMI=FFM/height). ${ }^{2}$ Nutritional depletion was defined by the values of FFMI $<15 \mathrm{~kg} / \mathrm{m}^{2}$ for women and $<16 \mathrm{~kg} / \mathrm{m}^{2}$ for men. ${ }^{27}$ 


\section{Exercise tolerance}

The exercise tolerance was assessed by the distance walked in the 6-minute walk test, according to the criteria established by the American Thoracic Society. Those with chronic hypoxemia or presenting $\mathrm{SpO}_{2}<85 \%$ during the test were supplemented with oxygen by nasal cannula. ${ }^{28,29}$

\section{Sensation of dyspnea and comorbidities}

The intensity of dyspnea was assessed by the mMRC (Modified Medical Research Council) scale, which was validated for Portuguese. ${ }^{30}$ The comorbidities associated with COPD were assessed by the Charlson Comorbidity Index (CCI), developed to calculate the risk of death for patients with chronic disease. ${ }^{31}$ BODE index was calculated using the modal described by Celli. ${ }^{16}$

\section{Statistical analysis}

Descriptive statistics was used to describe the characteristics of all the participants. Continuous data were presented as mean and SD for the normally distributed variables, and those variables without normal distribution were presented as median and IQR. We used unpaired $t$-test or Mann-Whitney test according to the distribution of the variable, in order to compare two groups using GOLD classification by $\mathrm{FEV}_{1}$ (I/II vs III/IV) or survival condition (survivors vs non-survivors). The chi-squared test was used to evaluate two qualitative binary variables with a frequency greater than five. The survival curves were plotted using the Kaplan-Meier curve followed by log-rank test to compare the GOLD by $\mathrm{FEV}_{1}$ classification, BODE index, and BMI ( $\geq 21 \mathrm{vs}<21 \mathrm{~kg} / \mathrm{m}^{2}$ ). Cox proportional hazard regression analysis was used to identify the predictors of mortality, including 110 patients who had all assessments during the period. All models were adjusted by sex, age, $\mathrm{SpO}_{2}, \mathrm{BODE}$ index, CCI, and number of exacerbations in first 3 years. A 5\% significance level was adopted for all the tests, with the following statistical packages: SigmaStat version 3.5 (Systat Software Inc., San Jose, CA, USA) and Stata 13.0 (StataCorp LP, College Station, TX, USA).

\section{Results}

Of the 133 patients included at the beginning of the study (69\% male, 65 \pm 9.5 years old, and $\mathrm{FEV}_{1}: 59.7 \% \pm 24.9 \%$ ), 19 stopped follow-up and 4 did not have their cause of death identified; therefore, 110 patients ( $67 \%$ male, $65 \pm 9$ years old, and $\left.\mathrm{FEV}_{1}: 52.5[40 \%-73 \%]\right)$ were included in the mortality analysis (Figure 1; Table 1). The classes of medications according to the 2004 GOLD classification are presented in Figure 2. We observed that at baseline, most patients were not using bronchodilators.

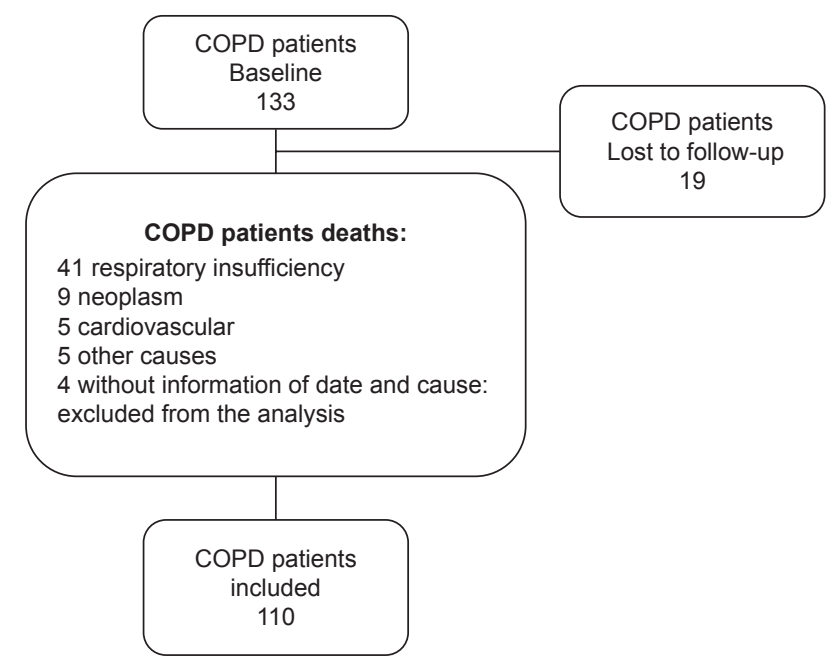

Figure I Flowchart of all patients included in the study.

The comparison between the initial characteristics of patients who survived and those who died are presented in Table 2. Of the 64 patients who died, at baseline, 7 were classified with mild COPD, 15 with moderate COPD, 12 with severe COPD, and 30 with very severe COPD, according to 2004 GOLD severity classification. Regarding the cause of death, $67 \%$ died mainly because of respiratory causes. The other causes of death are presented in Figure 3.

To evaluate the BODE index classes, GOLD severity classification according to 2004 guidelines and BMI $<21$ or $\geq 21 \mathrm{~kg} / \mathrm{m}^{2}$, we used Kaplan-Meier survival curves followed by log-rank test. We observed that patients with higher severity or BMI $<21 \mathrm{~kg} / \mathrm{m}^{2}$ showed worst mortality rate in 9 years (Figure 4 ).

To evaluate the factors associated with mortality in the Cox regression analysis model, male sex, age (years), $\mathrm{SpO}_{2}$ $(\%), \mathrm{CCI}$, and number of exacerbations in the first 3 years of follow-up were considered. When the BODE index was included in the model, the analysis showed that patients classified in the initial assessment with BODE classes 2 and 3 are two times more likely to die in 9 years compared to the group of patients with BODE class 1. When patients with BODE class 4 were compared to those with class 1 , they presented a 15 times higher risk of death. In addition, the CCI and the number of exacerbations were also associated with increased risk of mortality (Table 3).

By replacing the BODE index for the variables that compose it, those with BMI $\leq 21 \mathrm{~kg} / \mathrm{m}^{2}$ showed a 2.7 times higher risk of death compared to those with BMI $>21 \mathrm{~kg} / \mathrm{m}^{2}$. The number of exacerbations remained statistically significant in the model of predictors of mortality, with the same value of HR (1.38 [1.03-1.85]), as shown in Table 4. When we replaced $\mathrm{FEV}_{1}$ by disease severity according to GOLD 
Table I Demographic and clinical characteristics of the patients included in the analysis of predictors of mortality according to FEV, (GOLD classification of FEV, severity) of COPD at baseline

\begin{tabular}{|c|c|c|c|c|}
\hline Variable & $\begin{array}{l}\text { Total } \\
(\mathrm{N}=|| 0)\end{array}$ & $\begin{array}{l}\text { COPD } \\
\text { GOLD I and } 2 \\
n=53\end{array}$ & $\begin{array}{l}\text { COPD } \\
\text { GOLD } 3 \text { and } 4 \\
n=57\end{array}$ & $P$-value \\
\hline Male/female sex, $n$ & $74 / 36$ & $33 / 20$ & $41 / 16$ & $0.38 I^{\mathrm{a}}$ \\
\hline Age, years & $65(59-72)$ & $65(59-73)$ & $67(61.5-73)$ & $0.536^{\mathrm{b}}$ \\
\hline SB, pack-years & $50(35-67)$ & $50(40-7 \mid .5)$ & $50(30-59)$ & $0.173^{b}$ \\
\hline $\mathrm{SpO}_{2}, \%$ & $94(92-96)$ & 94 (93-97) & $93(9 \mid-95)$ & $0.003^{b}$ \\
\hline $\mathrm{FEV}_{1}, \%$ of the predicted & $52.5(40-73)$ & $73(60-87.5)$ & $40(32.5-46.5)$ & $<0.00 I^{\mathrm{b}}$ \\
\hline $\mathrm{FEV}_{1}, \mathrm{~L}$ & $1.20(0.93-1.72)$ & $1.65(1.32-2.14)$ & $0.94(0.75-1.09)$ & $<0.00 I^{\mathrm{b}}$ \\
\hline $\mathrm{BMI}, \mathrm{kg} / \mathrm{m}^{2}$ & $25(21-28)$ & $25.8(2|.7-3| . \mid)$ & $24.4(20.7-27.4)$ & $0.097^{b}$ \\
\hline Fat-free mass, $\mathrm{kg}$ & $42(7)$ & $41.5(7.4)$ & $41.9(7.1)$ & $0.787^{c}$ \\
\hline mMRC, score & $I(I-2)$ & I (I-2) & $2(I-3)$ & $0.006^{\mathrm{b}}$ \\
\hline 6MWT, m & $430(91)$ & $457(85)$ & 404 (89) & $0.002^{c}$ \\
\hline BODE, class & $I(I-2)$ & $I(I-I)$ & $2(I-3)$ & $<0.00 I^{\mathrm{b}}$ \\
\hline
\end{tabular}

Notes: Parametric data are expressed as mean and SD and nonparametric data as median (IQR 25-75). The 2004 GOLD classification of airflow limitation severity - GOLD I or GOLD 2 vs GOLD 3 or GOLD 4 ( ${ }^{a}$ chi-squared test, ' Mann-Whitney, or 'unpaired t-test). BODE index: class I (score 0-2), class 2 (score 3 and 4 ), class 3 (score 5 and 6 ), and class 4 (score 7-10).

Abbreviations: 6MWT, 6-minute walk test; BMI, body mass index; BODE, Body mass index, airway Obstruction, Dyspnea, and Exercise capacity; SB, smoking burden; SpO, pulse oximetry; mMRC, Modified Medical Research Council.

(2004), we did not observe statistically significant risk factor associated with mortality (Table S1).

When patients with neoplasm were excluded from the survival analysis, the CCI was not anymore associated with increased risk of mortality, in both the Cox model that included the categorized BODE $(P=0.060)$ and in the model that replaced it by the variables that compose it $(P=0.074)$, as shown in Table S2.

\section{Discussion}

This study mainly aimed to assess the predictors of mortality in patients with COPD in a 9-year period, and before this, it was possible to reinforce previous findings about the importance of the BODE index. We observed that, the higher the classification in the index, the greater the risk of death, and BODE class 4 patients were 15 times more likely to die compared to class 1 patients.

Analogous to our findings, the study by Martinez et al ${ }^{14}$ with 610 patients with severe COPD using pharmacological therapy and 608 surgically treated patients has shown that increase in the BODE index higher than 1 point in relation to the baseline after 2 years of follow-up was associated with increased risk of death in both groups. Similarly, Moberg et $\mathrm{al}^{15}$ conducted a follow-up of 674 Danish patients

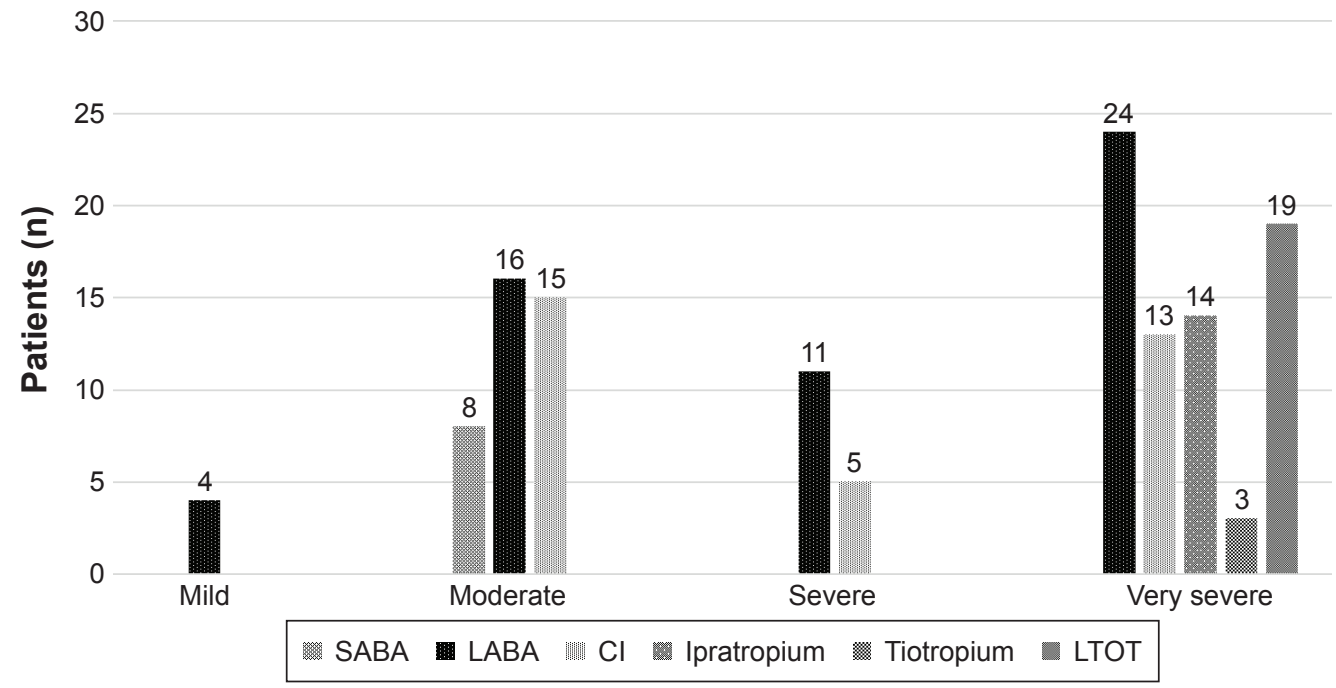

Figure 2 Medication classes used at baseline according to the GOLD classification.

Abbreviations: LABA, long-acting beta 2 agonists; LTOT, long-term oxygen therapy; SABA, short-acting beta 2 agonists. 
Table 2 Comparison between the baseline characteristics according to survival status (survivors vs non-survivors) after 9 years

\begin{tabular}{|c|c|c|c|c|}
\hline Variable & Total $(\mathbf{N}=|1| 0)$ & Survivors $(n=46)$ & Non-survivors $(n=64)$ & $P$-value \\
\hline Male/female sex, $n$ & $75 / 35$ & $28 / 18$ & $47 / 17$ & $0.235^{\mathrm{a}}$ \\
\hline Age, years & $65(9.4)$ & $61.5(8.7)$ & $67.6(9)$ & $<0.00 \mathrm{I}^{\mathrm{b}}$ \\
\hline SB, pack-years & $50(34.7-70)$ & $43(30-75)$ & $50(40-69)$ & $0.616^{c}$ \\
\hline $\mathrm{SpO}_{2}, \%$ & $93(92-96)$ & $94(92.7-96)$ & $93(9 \mid-95)$ & $0.035^{c}$ \\
\hline $\mathrm{FEV}_{1}, \%$ of the predicted & $52.5(39-73.2)$ & 61 (46.5-79) & $46(37-64.7)$ & $0.004^{c}$ \\
\hline $\mathrm{FEV}_{1}, \mathrm{~L}$ & I.2I (0.94-I.7I) & $1.47(0.99-1.92)$ & $1.10(0.86-1.48)$ & $0.020^{c}$ \\
\hline $\mathrm{BMI}, \mathrm{kg} / \mathrm{m}^{2}$ & $25(2 I-28)$ & $25.4(22.3-28.6)$ & $24.5(20.6-28)$ & $0.142^{c}$ \\
\hline Fat-free mass, $\mathrm{kg}$ & $41.6(7.3-0.7)$ & $4 \mid(7)$ & $42(7.5)$ & $0.556^{\mathrm{b}}$ \\
\hline mMRC, score & $\mathrm{I}(\mathrm{I}-2)$ & $I(I-2)$ & $2(I-2)$ & $0.076^{c}$ \\
\hline 6MWT, m & $429(94.2)$ & $46 \mid(90.4)$ & $406(90.6)$ & $0.002^{b}$ \\
\hline BODE, class & $\mid(\mid-2)$ & $\mathrm{I}(\mathrm{I}-\mathrm{I} .2)$ & $2(I-3)$ & $<0.001^{c}$ \\
\hline
\end{tabular}

Notes: Parametric data are expressed as mean and SD and nonparametric as median (IQR 25-75). ${ }^{a}$ Chi-squared test, ${ }^{b}$ unpaired $t$-test, or ${ }^{c}$ Mann-Whitney. BODE index: class I (score 0-2), class 2 (score 3 and 4), class 3 (score 5 and 6), and class 4 (score 7-10).

Abbreviations: 6MWT, 6-minute walk test; BMI, body mass index; BODE, Body mass index, airway Obstruction, Dyspnea, and Exercise capacity; SB, smoking burden; SpO pulse oximetry; mMRC, Modified Medical Research Council.

with COPD in an average period of 66 months (interval of 11-118 months). The authors replaced the 6-minute walk test by the Shuttle Walking Test (i-BODE) and observed that the index was significantly associated with all causes of mortality, exacerbation, and hospitalization. On the other hand, the study by Zemans et al ${ }^{32}$ concluded that the combination of biomarkers produces more highly predictive models than individual analysis or the clinical variables already widely established. In addition, according to Locantore et al, ${ }^{33}$ the addition of inflammatory biomarkers such as IL-6 and CRP in predictive models significantly increases the capacity of the BODE index, which suggests that laboratory variables must be used along with clinical variables to strengthen the predictive models of COPD mortality.

Regarding the GOLD classification, our study did not identify an association of disease severity with mortality by the criteria of 2004 GOLD, but it is known that it predicts exacerbations and mortality both in general and specific populations ${ }^{1,34}$ with the modifications that took place in the GOLD classification over time. Lange et $a{ }^{35}$ have shown that 6,608 patients with COPD monitored during the average time of 4.3 years presented a higher risk of exacerbation and mortality, according to the $\mathrm{ABCD}$ assessment tool. The PLATINO $^{36}$ study, which analyzed the mortality rate in 524 patients with COPD from 2007 to 2017, has shown that the 2007 GOLD classification showed a positive association of mortality with increased airflow obstruction, whereas in the 2013 GOLD and 2017 GOLD, higher mortality rates were observed in groups $\mathrm{C}$ and $\mathrm{D}$.

However, in our study, 2004 GOLD was not predictive of mortality, and this may have occurred because this classification only considers airflow obstruction and, here, the values

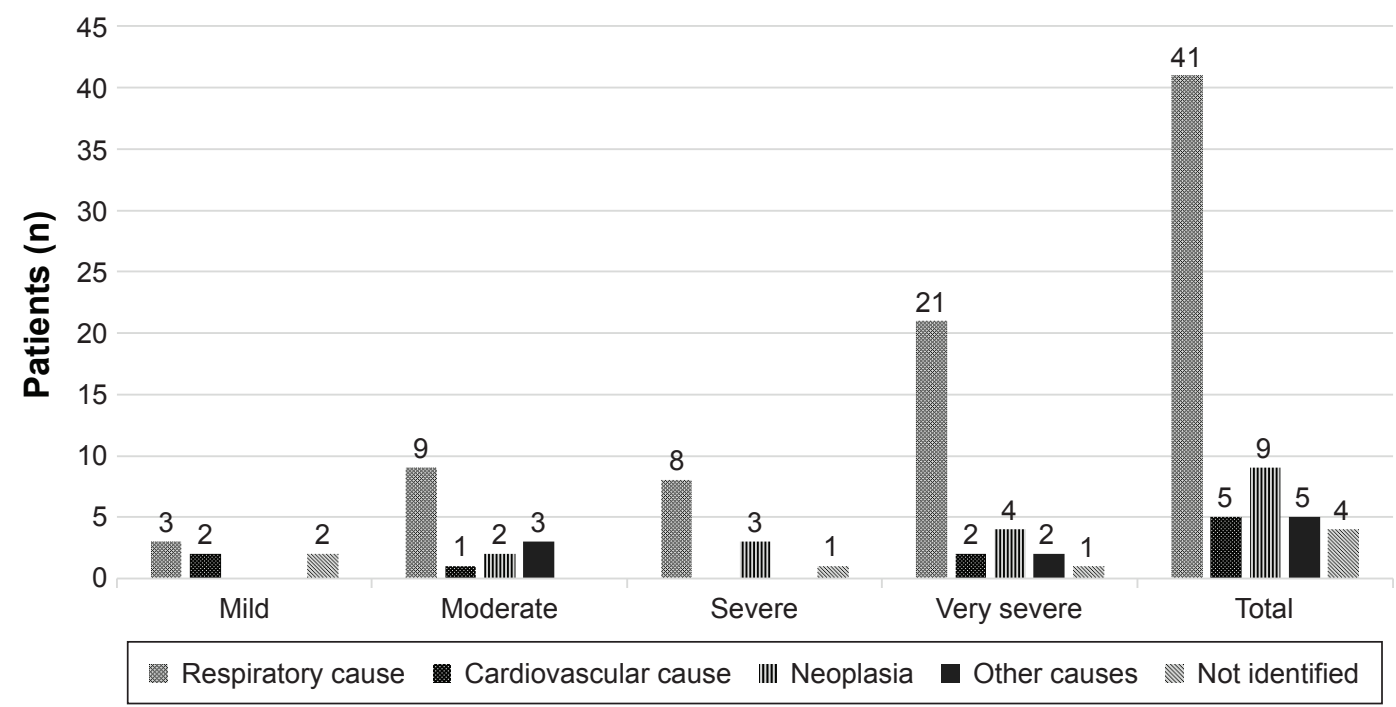

Figure 3 Causes of death according to severity of COPD. 

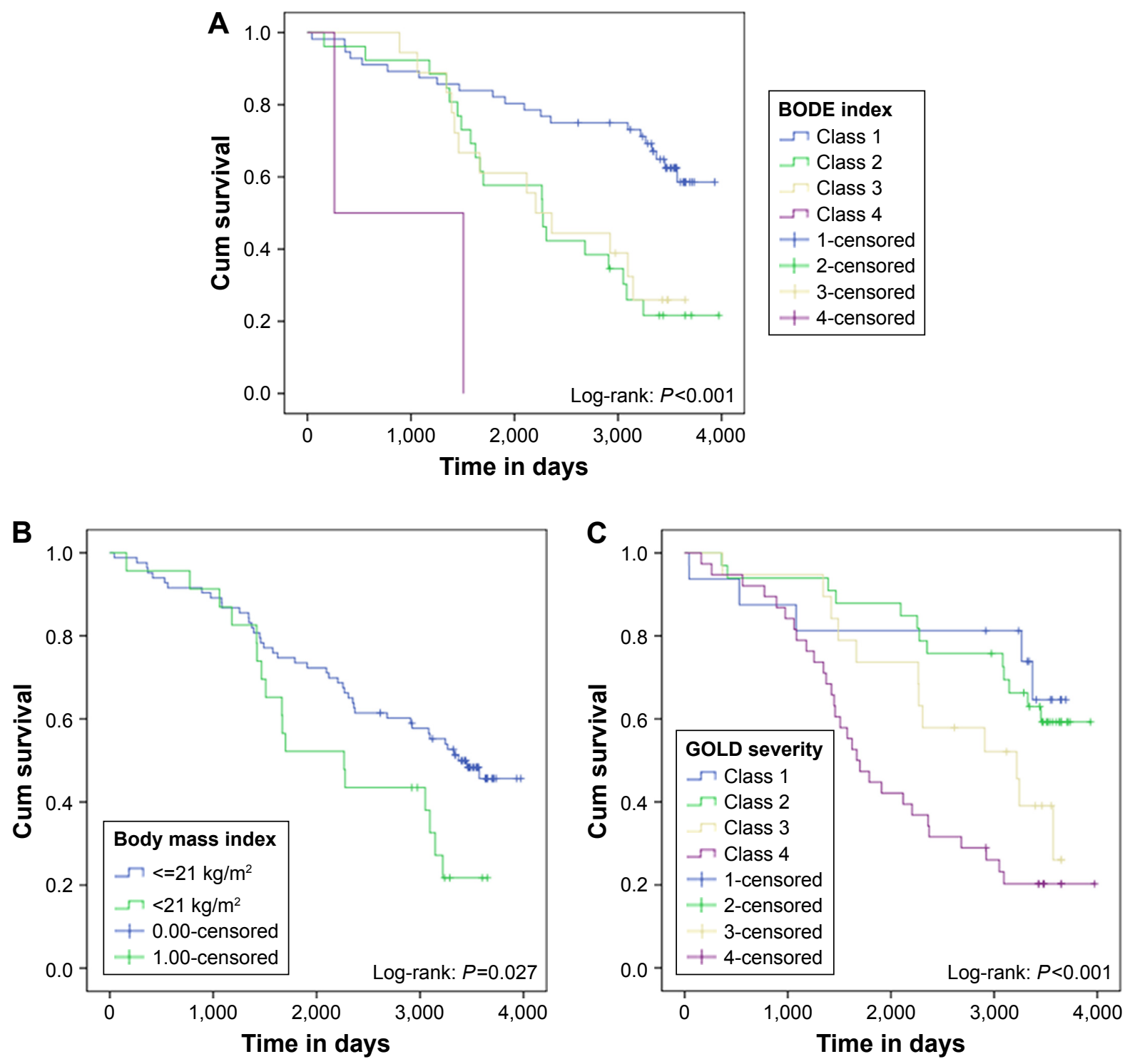

Figure 4 Kaplan-Meier survival curves of all patients according to BODE index classification (A) body mass index (B) and 2004 GOLD severity classification (C) Abbreviation: BODE, Body mass index, airway Obstruction, Dyspnea, and Exercise capacity.

of $\mathrm{FEV}_{1}$ were only a little above $50 \%$, not characterizing the population as severe or very severe. In addition, the isolated analysis of $\mathrm{FEV}_{1}$ was not predictive of mortality in this population; however, it is already known that its predictive value is weak when it is higher than $50 \%$, not being a good predictor of mortality on its own. ${ }^{16,37}$ This differs from the results of the PLATINO ${ }^{13}$ study, conducted in three cities of Latin America with $>3,000$ patients and with a population-based cohort for 5,6 , and 9 years, which showed that the presence of COPD and low values of $\mathrm{FEV}_{1}$ at baseline were important predictors of overall and cardiovascular mortality. Similar to our findings, a study with 707 patients with COPD, monitored for $\sim 50$ months, showed that the BODE index was a better predictor of the survival of these individuals than the GOLD categories ABCD.${ }^{38}$ Similarly, Botella et al,,${ }^{39}$ who monitored 96 patients with COPD for about 60 months, found that the BODE index was a better predictor of mortality than 2007 GOLD and GOLD ABCD.

In addition, the $\mathrm{CCI}$ and the number of exacerbations were also equally associated with increased risk of mortality. Likewise, a retrospective study conducted from 2009 to 2014 with 612 patients with COPD showed that the CCI was a predictor of mortality when a multivariate analysis was performed..$^{10}$ Regarding exacerbation, in this study, patients who had more exacerbations in the first 3 years of follow-up were 1.3 times more likely to die compared to those who had no exacerbation. In the same direction, the study by SolerCataluña et $\mathrm{al}^{40}$ with 304 patients with COPD monitored for 
Table 3 Cox regression analysis to identify the predictors of mortality in the 9-year period

\begin{tabular}{l|l|l}
\hline Variables & $\begin{array}{l}\text { HR (95\% CI), } \\
\text { N=I I 0 }\end{array}$ & $P$-value \\
\hline Male & $\mathrm{I} .34(0.68-2.63)$ & 0.390 \\
Age (years) & $0.98(0.93-1.03)$ & 0.610 \\
$\mathrm{SPO}_{2}(\%)$ & $0.94(0.85-1.04)$ & 0.258 \\
$\mathrm{BODE}$ index class I - reference & $*$ & $*$ \\
$\mathrm{BODE}$ index class 2 & $2.62(\mathrm{I} .36-5.04)$ & 0.004 \\
BODE index class 3 & $2.54(1.15-5.6 \mathrm{I})$ & $0.02 \mathrm{I}$ \\
BODE index class 4 & $\mathrm{I} 5.35(3.1 \mathrm{I}-75.75)$ & $0.00 \mathrm{I}$ \\
Charlson Comorbidity Index & $\mathrm{I} .29(\mathrm{I} .00-1.68)$ & 0.049 \\
Exacerbation $(\mathrm{n})$ & $\mathrm{I} .32(\mathrm{I} .00-1.76)$ & 0.048 \\
\hline
\end{tabular}

Notes: All variables were included together in the Cox proportional hazard regression analysis (sex, age, $\mathrm{SpO}_{2}, \mathrm{BODE}$ index, $\mathrm{CCl}$, and number of exacerbations in the first 3 years). BODE exacerbation, number of exacerbations in the 3-year period of follow-up; index, class I (score 0-2), class 2 (score 3 and 4), class 3 (score 5 and 6), and class 4 (score 7-10).

Abbreviations: BODE, Body mass index, airway Obstruction, Dyspnea, and Exercise capacity; $\mathrm{SpO}_{2}$, pulse oximetry.

5 years reported that patients with three or more acute exacerbations of COPD had 4.1 times higher risk of death compared to those without exacerbation. Vanasse et $\mathrm{al},{ }^{41}$ in a cohort with $>1,100$ patients with COPD, identified that both severe exacerbations of COPD (2.5 odds ratio [OR]) and higher CCI (1.2 OR) were predictors of mortality 1 year after hospital discharge, along with other factors such as old age, male sex, longer hospitalization, cancer diagnosis, higher number of previous hospitalizations, and diagnosis of COPD older than 3 years. Thus, characteristically, patients who presented higher association of comorbidities show additional effects in the risk of mortality. When cancer patients were excluded from the survival Cox analysis, we observed that CCI was

Table 4 Cox regression analysis with replacement of the BODE index for the variables that compose it

\begin{tabular}{l|l|l}
\hline Variables & $\begin{array}{l}\text { HR (95\% Cl), } \\
\text { N=I I } 0\end{array}$ & P-value \\
\hline Male & $1.36(0.66-2.76)$ & 0.396 \\
Age (years) & $0.97(0.93-1.03)$ & 0.434 \\
$\mathrm{SpO}_{2}(\%)$ & $0.93(0.84-1.03)$ & 0.170 \\
$6 \mathrm{MWT}(\mathrm{m})$ & $0.99(0.99-1.00)$ & 0.305 \\
$\mathrm{FEV}_{1}(\%)$ & $0.99(0.97-1.00)$ & 0.417 \\
$\mathrm{BMI}>2 \mathrm{I} \mathrm{kg} / \mathrm{m}^{2}$ (reference) & $*$ & $*$ \\
$\mathrm{BMI}\left(\leq 2 \mathrm{lg} / \mathrm{m}^{2}\right)$ & $2.70(1.38-5.25)$ & 0.003 \\
$\mathrm{mMRC}($ score $)$ & $1.06(0.75-1.50)$ & 0.730 \\
CCl & $1.29(0.99-1.68)$ & 0.057 \\
Exacerbation $(\mathrm{n})$ & $1.38(1.03-1.85)$ & 0.027 \\
\hline
\end{tabular}

Notes: All variables were included together in the Cox proportional hazard regression (sex, age, $\mathrm{SpO}_{2}, 6 \mathrm{MWT}$, BMl, mMRC, $\mathrm{CCl}$, and number of exacerbations in first 3 years). Exacerbation, number of exacerbations per patient in the 3-year period.

Abbreviations: 6MWT, 6-minute walk test; BMI, body mass index; BODE, Body mass index, airway Obstruction, Dyspnea, and Exercise capacity; CCl, Charlson Comorbidity Index; $\mathrm{SpO}_{2}$, pulse oximetry; mMRC, Modified Medical Research Council. not statistically significant. We can speculate that cancer patients have higher CCI score than patients without cancer, such as the COPD Lung Cancer Screening Score that includes age $>60$ years, pack-years $>60$, and BMI $<25 \mathrm{~kg} / \mathrm{m}^{2}$. Both scores use age to compute higher score, and these patients can have higher risk factor for all types for cancer. Unfortunately, we did not have genetic studies to evaluate the risk of cancer for these patients. ${ }^{42}$

Finally, we found that patients with BMI $\leq 21 \mathrm{~kg} / \mathrm{m}^{2}$ were 2.7 times more likely to die compared to those with BMI $>21 \mathrm{~kg} / \mathrm{m}^{2}$. Similar to our results, a meta-analysis performed by Cao et al, ${ }^{11}$ which included 22 studies with a total sample of 21,150 individuals, showed that individuals with low weight (BMI $<20$ or $21 \mathrm{~kg} / \mathrm{m}^{2}$ ) were associated with higher mortality (relative risk of 1.34). Yang et a ${ }^{12}$ showed, in a study conducted with 221,194 Chinese patients aged between 40 and 79 years and monitored for 15 years or until the age of 80 , that, of the 8,769 COPD-related deaths, individuals with low BMI $\left(<20 \mathrm{~kg} / \mathrm{m}^{2}\right)$ were associated with higher risk of mortality. It is observed that patients with lower body weight have a higher risk of mortality and, besides, the influence that a higher BMI exerts on aspects such as better pulmonary function, greater reduction in the sensation of dyspnea, and better quality of life is well reported. ${ }^{43}$ Moreover, the study by Wei et al ${ }^{14}$ showed that higher body weight and obesity were related with a lower frequency of exacerbation of COPD in 1,096 Taiwanese patients. Similarly, Geva et al, ${ }^{45}$ who monitored 323 patients with COPD from 2003 to 2010, found that being male and obese were the protection factors against exacerbations; however, in their study, obesity did not affect the survival of those patients. Therefore, nutritional depletion is linked with other clinical outcomes of COPD that are interrelated with the negative outcomes of the disease. However, this can be a feature that may receive intensive clinical intervention to reduce its negative effect on mortality.

This study presents as limitations, in addition to the loss of follow-up of $\sim 17 \%$, the failure to identify all the causes of death of the patients, which may jeopardize the interpretations of the causes related to the severity of the disease. Thus, in future studies, it is suggested to increase the sample size to confirm our results. Despite the small sample size, we can identify that the clinical characteristics of the patients with COPD can be related to mortality over 9 years of follow-up. However, further longitudinal studies are needed to confirm the findings of this study. We highlight that we did not aim to identify cause and effect, which means that we can only affirm the possible associations of the characteristics presented with the mortality of patients with COPD. 


\section{Conclusion}

By evaluating the predictors of mortality in patients with COPD in a 9-year period, we identified that those with high BODE index, greater CCI, higher frequency of exacerbations in the first 3 years, and BMI $\leq 21 \mathrm{~kg} / \mathrm{m}^{2}$ showed increased risk of death.

\section{Disclosure}

The authors report no conflicts of interest in this work.

\section{References}

1. Vogelmeier CF, Criner GJ, Martinez FJ, et al. Global Strategy for the Diagnosis, Management, and Prevention of Chronic Obstructive Lung Disease 2017 Report. GOLD Executive Summary. Am J Respir Crit Care Med. 2017;195(5):557-582.

2. World Health Organization. The Global Burden of Disease. 2004 update. Geneva: WHO; 2008. Available from: http://bit.ly/1xflsSf. Accessed January 12, 2017.

3. Jardim JR, Oliveira JA, Nascimento O. II Consenso Brasileiro de DPOC [II Brazilian Consensus on Chronic Obstructive Pulmonary Disease (COPD)]. J Bras Pneumol. 2004;30(Suppl 1):S1-S42.

4. Graudenz GS, Gazotto GP. Mortality trends due to chronic obstructive pulmonary disease in Brazil. Rev Assoc Med Bras. 2014;60(3):255-261.

5. Rodriguez-Roisin R. Toward a consensus definition for COPD exacerbations. Chest. 2000;117(5 Suppl 2):398S-401S.

6. Takechi Y. Intervention for COPD Exacerbation - how to prevent and treat COPD exacerbation? Gan To Kagaku Ryoho. 2016;43(Suppl 1):61-63.

7. Jezler S, Holanda MA, José A, Franca S. Mechanical ventilation in decompensated chronic obstructive pulmonary disease (COPD). J Bras Pneumol. 2007;33(Suppl 2):S111-S118.

8. Holguin F, Folch E, Redd SC, Mannino DM. Comorbidity and mortality in COPD-related hospitalizations in the United States, 1979 to 2001. Chest. 2005;128(4):2005-2011.

9. Terzano C, Conti V, di Stefano F, et al. Comorbidity, hospitalization, and mortality in COPD: results from a longitudinal study. Lung. 2010; 188(4):321-329.

10. Golpe R, Mengual-Macenlle N, Sanjuán-López P, et al. Prognostic indices and mortality prediction in COPD caused by biomass smoke exposure. Lung. 2015;193(4):497-503.

11. Cao C, Wang R, Wang J, Bunjhoo H, Xu Y, Xiong W. Body mass index and mortality in chronic obstructive pulmonary disease: a meta-analysis. PLoS One. 2012;7(8):e43892.

12. Yang L, Zhou M, Smith M, et al. Body mass index and chronic obstructive pulmonary disease-related mortality: a nationally representative prospective study of 220,000 men in China. Int J Epidemiol. 2010;39(4): 1027-1036.

13. Menezes AM, Pérez-Padilla R, Wehrmeister FC, et al. FEV1 is a better predictor of mortality than FVC: the PLATINO cohort study. PLoS One. 2014;9(10):e109732.

14. Martinez FJ, Han MK, Andrei AC, et al. Longitudinal change in the BODE index predicts mortality in severe emphysema. Am J Respir Crit Care Med. 2008;178(5):491-499.

15. Moberg M, Vestbo J, Martinez G, et al. Validation of the i-BODE index as a predictor of hospitalization and mortality in patients with COPD participating in pulmonary rehabilitation. COPD. 2014;11(4):381-387.

16. Celli BR. Predictors of mortality in COPD. Respir Med. 2010;104(6): 773-779.

17. García-Sanz MT, Cánive-Gómez JC, Senín-Rial L, et al. One-year and long-term mortality in patients hospitalized for chronic obstructive pulmonary disease. J Thorac Dis. 2017;9(3):636-645.

18. Esteban C, Quintana JM, Aburto M, et al. Predictors of mortality in patients with stable COPD. J Gen Intern Med. 2008;23(11):1829-1834.
19. Ferrari R, Tanni SE, Faganello MM et al. Three-year follow-up study of respiratory and systemic manifestations of chronic obstructive pulmonary disease. Braz J Med Biol Res. 2011;44(1):46-52.

20. Toyoshima MTK, Ito GM, Gouveia N. Tendências temporais da morbidade e da mortalidade por doenças respiratórias na cidade de São Paulo [Temporal trends in morbidity and mortality for respiratory diseases in São Paulo, Brazil]. Rev Med. 2003;82(1-4):67-77.

21. Machado MC, Krishnan JA, Buist SA, et al. Sex differences in survival of oxygen-dependent patients with chronic obstructive pulmonary disease. Am J Respir Crit Care Med. 2006;174(5): 524-529.

22. Menezes AMB, Jardim JR, Pérez-Padilla R, et al. Prevalence of chronic obstructive pulmonary disease and associated factors: the PLATINO study in São Paulo, Brazil. Cad Saude Publica. 2005;21(5): $1565-1573$.

23. Standardization of spirometry-1987 update. Statement of the American Thoracic Society. Am Rev Respir Dis. 1987;136:1285-1298.

24. Knudson RJ, Lebowitz MD, Holberg CJ, Burrows B. Changes in the normal maximal expiratory flow-volume curve with growth and aging. Am Rev Respir Dis. 1983;127(6):725-734.

25. Kyle UG, Bosaeus I, de Lorenzo AD, et al. Bioelectrical impedance analysis - part I: review of principles and methods. Clin Nutr. 2004; 23(5):1226-1243.

26. Kyle UG, Pichard C, Rochat T, Slosman DO, Fitting JW, Thiebaud D. New bioelectrical impedance formula for patients with respiratory insufficiency: comparison to dual-energy X-ray absorptiometry. Eur Respir J. 1998;12(4):960-966.

27. Schols AM, Broekhuizen R, Weling-Scheepers CA, Wouters EF. Body composition and mortality in chronic obstructive pulmonary disease. Am J Clin Nutr. 2005;82(1):53-59.

28. Crapo RO, Casaburi R, Coates AL; ATS Committee on Proficiency Standards for Clinical Pulmonary Function Laboratories. ATS statement: guidelines for the six-minute walk test. Am J Respir Crit Care Med. 2002;166(1):111-117.

29. Redelmeier DA, Bayoumi AM, Goldstein RS, Guyatt GH. Interpreting small differences in functional status: the Six Minute Walk test in chronic lung disease patients. Am J Respir Crit Care Med. 1997;155(4): $1278-1282$.

30. Kovelis D, Segretti NO, Probst VS, Lareau SC, Brunetto AF, Pitta F. Validação do Modified Pulmonary Functional Status and Dyspnea Questionnaire e da escala do Medical Research Council para o uso em pacientes com doença pulmonar obstrutiva crônica no Brasil [Validation of the Modified Pulmonary Functional Status and Dyspnea Questionnaire and the Medical Research Council scale for use in Brazilian patients with chronic obstructive pulmonary disease]. J Bras Pneumol. 2008;34(12):1008-1018.

31. Charlson M, Szatrowski TP, Peterson J, Gold J. Validation of a combined comorbidity index. J Clin Epidemiol. 1994;47(11):1245-1251.

32. Zemans RL, Jacobson S, Keene J, et al. Multiple biomarkers predict disease severity, progression and mortality in COPD. Respir Res. 2017; 18(1):1-10.

33. Locantore N, Celli B, Agusti A, et al. The Bode index and Bode Plus Biomarkers as predictors of long-term survival in COPD. Am J Respir Crit Care Med. 2016;193:A3482.

34. Chan HP, Mukhopadhyay A, Chong PL, et al. Prognostic utility of the 2011 GOLD classification and other multidimensional tools in Asian COPD patients: a prospective cohort study. Int J Chron Obstruct Pulmon Dis. 2016;11:823-829.

35. Lange P, Marott JL, Vestbo J, et al. Prediction of the clinical course of chronic obstructive pulmonary disease, using the new GOLD classification: a study of the general population. Am J Respir Crit Care Med. 2012;186(10):975-981.

36. Menezes AM, Wehrmeister FC, Perez-Padilla R, et al. The PLATINO study: description of the distribution, stability, and mortality according to the Global Initiative for Chronic Obstructive Lung Disease classification from 2007 to 2017. Int J Chron Obstruct Pulmon Dis. 2017;12:1491-1501. 
37. Fletcher C, Peto R. The natural history of chronic airflow obstruction. Br Med J. 1977;1(6077):1645-1648.

38. de Torres JP, Casanova C, Marín JM, et al. Prognostic evaluation of COPD patients: GOLD 2011 versus BODE and the COPD comorbidity index COTE. Thorax. 2014;69(9):799-804.

39. Botella JB, Pinto-Plata V, Divo M. The BODE index predicts mortality better than 2007 GOLD and GOLD ABCD. Eur Respir J. 2014;44: P533.

40. Soler-Cataluña JJ, Martínez-García MA, Román Sánchez P, Salcedo E, Navarro M, Ochando R. Severe acute exacerbations and mortality in patients with chronic obstructive pulmonary disease. Thorax. 2005;60(11): 925-931.

41. Vanasse A, Courteau J, Couillard S, Beauchesne MF, Larivée P. Predicting one-year mortality after a "first" hospitalization for chronic obstructive pulmonary disease: an eight-variable assessment score tool. COPD. 2017;14(5):490-497.
42. de-Torres JP, Marín JM, Casanova C, et al. Identification of COPD patients at high risk for lung cancer mortality using the COPD-LUCSSDLCO. Chest. 2016;149(4):936-942.

43. Lim JU, Lee JH, Kim JS, et al. Comparison of World Health Organization and Asia-Pacific body mass index classifications in COPD patients. Int J Chron Obstruct Pulmon Dis. 2017;12(12):2465-2475.

44. Wei YF, Tsai YH, Wang CC, Kuo PH. Impact of overweight and obesity on acute exacerbations of COPD - subgroup analysis of the Taiwan Obstructive Lung Disease cohort. Int J Chron Obstruct Pulmon Dis. 2017;12(12):2723-2729.

45. Geva S, Yaakob M, Kalchiem-Dekel O. The association between obesity and chronic obstructive pulmonary disease (COPD). Harefuah. 2016;55(9):554-558. 


\section{Supplementary materials}

Table SI Cox regression analysis with GOLD severity classification to identify the predictors of mortality in the 9-year period

\begin{tabular}{|c|c|c|}
\hline Variables & $\begin{array}{l}\text { HR }(95 \% \mathrm{Cl}) \\
\mathrm{N}=110\end{array}$ & $P$-value \\
\hline Male & $1.25(0.64-2.55)$ & 0.536 \\
\hline Age (years) & $0.98(0.92-1.03)$ & 0.465 \\
\hline $\mathrm{SpO}_{2}(\%)$ & $0.96(0.85-1.08)$ & 0.521 \\
\hline 6MWT (m) & $0.99(0.99-1.00)$ & 0.625 \\
\hline $\mathrm{BMI}>2 \mathrm{l} \mathrm{kg} / \mathrm{m}^{2}$ & $0.96(0.91-1.02)$ & 0.304 \\
\hline \multicolumn{3}{|c|}{ GOLD I - reference } \\
\hline GOLD 2 & $1.16(0.37-3.61)$ & 0.798 \\
\hline GOLD 3 & $1.63(0.53-4.99)$ & 0.390 \\
\hline GOLD 4 & $2.18(0.63-7.60)$ & 0.218 \\
\hline mMRC (score) & $1.13(0.80-1.59)$ & 0.481 \\
\hline $\mathrm{CCl}$ & $1.32(0.99-1.76)$ & 0.058 \\
\hline Exacerbation (n) & $1.24(0.92-1.69)$ & 0.153 \\
\hline
\end{tabular}

Notes: All variables were included together in the Cox proportional hazard regression (sex, age, $\mathrm{SpO}_{2}, 6 \mathrm{MWT}, \mathrm{BMI}, \mathrm{mMRC}, \mathrm{CCl}$, number of exacerbations in first 3 years, and 2004 GOLD classification of airflow limitation severity). Exacerbation, number of exacerbations per patient in the 3-year period.

Abbreviations: 6MWT, 6-minute walk test; BMI, body mass index; CCl, Charlson Comorbidity Index; SpO, pulse oximetry; mMRC, Modified Medical Research Council.

Table S2 Cox regression analysis with replacement of the BODE index for the variables that compose it, without patients with neoplasm, to identify the predictors of mortality in the 9-year period

\begin{tabular}{|c|c|c|}
\hline Variables & $\begin{array}{l}\text { HR }(95 \% \mathrm{Cl}) \\
\mathrm{N}=1 \mathrm{I} 0\end{array}$ & $P$-value \\
\hline Male & $0.29(0.64-2.78)$ & 0.428 \\
\hline Age (years) & $-0.20(0.93-1.03)$ & 0.464 \\
\hline $\mathrm{SpO}_{2}(\%)$ & $-0.04(0.85-1.07)$ & 0.430 \\
\hline 6MWT (m) & $-0.002(0.73-1.50)$ & 0.243 \\
\hline $\mathrm{FEV}_{1}(\%)$ & $-0.004(0.98-1.01)$ & 0.583 \\
\hline $\mathrm{BMI}<2 \mathrm{l} \mathrm{kg} / \mathrm{m}^{2}$ & $1.00(1.38-5.33)$ & 0.004 \\
\hline mMRC (score) & $0.48(0.73-1.50)$ & 0.794 \\
\hline $\mathrm{CCl}$ & $0.24(0.97-1.68)$ & 0.074 \\
\hline Exacerbation (n) & $0.38(1.08-1.99)$ & 0.013 \\
\hline
\end{tabular}

Notes: All variables were included together in the Cox proportional hazard regression (sex, age, $\mathrm{SpO}_{2}, 6 \mathrm{MWT}, \mathrm{BMI}, \mathrm{mMRC}, \mathrm{CCl}$, and number of exacerbations in first 3 years) without patients with neoplasm during the follow-up. Exacerbation, number of exacerbations per patient in the 3-year period.

Abbreviations: 6MWT, 6-minute walk test; BMI, body mass index; BODE, Body mass index, airway Obstruction, Dyspnea, and Exercise capacity; CCl, Charlson Comorbidity Index; $\mathrm{SpO}_{2}$, pulse oximetry; mMRC, Modified Medical Research Council.

\section{Publish your work in this journal}

The International Journal of COPD is an international, peer-reviewed journal of therapeutics and pharmacology focusing on concise rapid reporting of clinical studies and reviews in COPD. Special focus is given to the pathophysiological processes underlying the disease, intervention programs, patient focused education, and self management protocols.

\section{Dovepress}

This journal is indexed on PubMed Central, MedLine and CAS. The manuscript management system is completely online and includes a very quick and fair peer-review system, which is all easy to use. Visit $\mathrm{http}: / /$ www.dovepress.com/testimonials.php to read real quotes from published authors. 